\title{
DESARROLLO DE UN MÉTODO CUANTITATIVO PARA LA DETERMINACIÓN DE MISOPROSTOL ÁCIDO EN SUERO HUMANO
}

\author{
Development a quantitative method for the determination of misoprostol acid in human serum \\ Luis A. López \\ ${ }^{1}$ Laboratorio de Toxicología del Instituto de Medicina Legal del Ministerio Público
}

\section{RESUMEN}

Se llevó a cabo un estudio experimental de diseño longitudinal con el objetivo de desarrollar un método cuali-cuantitativo para la determinación de misoprostol éster a través de su metabolito misoprostol ácido en muestras de suero. Se empleó un Cromatógrafo Líquido de Ultraperformance con detector Masa-Masa (UPLC MS-MS), obteniéndose picos a los 2,2 minutos de desarrollo cromatográfico del misoprostol ácido y concentraciones que se encuentran entre 3,1 y 18,4 ppb.

Palabras clave: Misoprostol ácido, muestras de suero, cromatografía líquida, metabolito, extracción en fase sólida.

\section{SUMMARY}

Was made an experimental study with longitudinal design to develop a qualitative and quantitative method to determine misoprostol ester through its metabolite misoprostol acid in serum samples. An ultraperformance liquid chromatograph equipment with a mass-mass detector (UPLC MS-MS) was used, obtaining peaks at 2,2 minutes of chromatographic running and concentrations between 3,1 and 18,4 ppb.

Keywords: Misoprostol acid, serum samples, liquid chromatography, metabolite, solid phase extraction.

\section{INTRODUCCIÓN}

E presente trabajo tiene como objetivo desarrollar un método cuali-cuantitativo utilizando un Cromatógrafo Líquido de Ultraperformance con detector Masa-Masa (UPLC MSMS) ${ }^{1}$, para la determinación de misoprostol éster a través de su metabolito, el misoprostol ácido, en muestras de suero humano de mujeres gestantes quienes consumieron misoprostol éster con fines abortivos ${ }^{2}$. A nivel nacional no existe un método oficial, aunque internacionalmente existen métodos desarrollados para equipos similares ${ }^{3}$.

Según referencias bibliográficas la concentración de misoprostol éster alcanza picos a los 20 minutos de ingesta, pero según otras referencias no puede ser detectado en el plasmaaúna loscinco minutosluegodeladosisoral ${ }^{3,12}$. En el presente estudio tampoco pudo determinarse misoprostol éster en las muestras de suero presumiblemente debido a que es metabolizado a misoprostol ácido rápidamente.

El misoprostol éster (15deoxi-16-hidroxi-metil PGE1) (figura 1), es un análogo semi-sintético de la prostaglandina E1, desarrollado para la prevención y tratamiento de úlceras pépticas debido a sus propiedades anti-secretorias y de protección de la mucosa ${ }^{3,4}$. Se ha convertido en una droga importante en el área obstétrica y ginecológica debido a sus acciones en el inicio y maduración cervical ${ }^{5,6,7}$, uterotónica, inductiva del parto y en el manejo de la hemorragia posparto, además de tener las ventajas de ser económico, no tener efectos sobre bronquios o vasos sanguíneos, presentar pocos efectos colaterales (diarrea y escalofríos, dependientes de la dosis y la persona), ser aplicable por vía oral, vaginal, sublingual o rectal ${ }^{8}$ y mantenerse estable por largos períodos a temperatura ambiente en su formulación farmacéutica.
Otras de sus aplicaciones clínicas incluyen el aborto medicamentoso, evacuación médica en aborto involuntario e inducción cervical antes del procedimiento de aborto quirúrgico, de lo cual se entiende su empleo fuera del contexto médico en prácticas abortivas clandestinas ${ }^{2,4}$.

\section{MATERIAL Y MÉTODOS}

El estudio es de tipo experimental y diseño longitudinal.

\section{Muestras y pre-tratamiento}

Para los ensayos se emplearon dos formas de extracción para el pre-tratamiento de las muestras. Los que utilizaron el método líquido-líquido con varios solventes orgánicos, puros y mezclas, dieron resultados no reproducibles. Los ensayos con cartuchos de extracción en fase sólida (SPE) ${ }^{9}$ utilizaron, para el pretratamiento de muestras biológicas, cartuchos: (a) LC-18, (b) LC-8 y (c) de balance hidrofílico-lipofílico, de intercambio catiónico y aniónico (HLB), cada uno de $3 \mathrm{mLy}$ $30 \mathrm{mg}$, los cuales fueron evaluados siguiendo los protocolos recomendados por sus fabricantes. Se obtuvieron resultados reproducibles con los cartuchos HLB.

\section{Toma de Muestra}

Se recibieron las muestras de sangre o suero, congeladas, tomadas en las diferentes sedes del Instituto de Medicina Legal a nivel nacional. Luego de centrifugar y separar el suero cuando fue requerido, las muestras fueron aceptadas para el análisis.

\section{Desarrollo del método}

\section{Cromatografía líquida}

Para obtener un pico simétrico y un tiempo de retención de 2,2 min (figura 2 ), se ensayaron varias mezclas de 


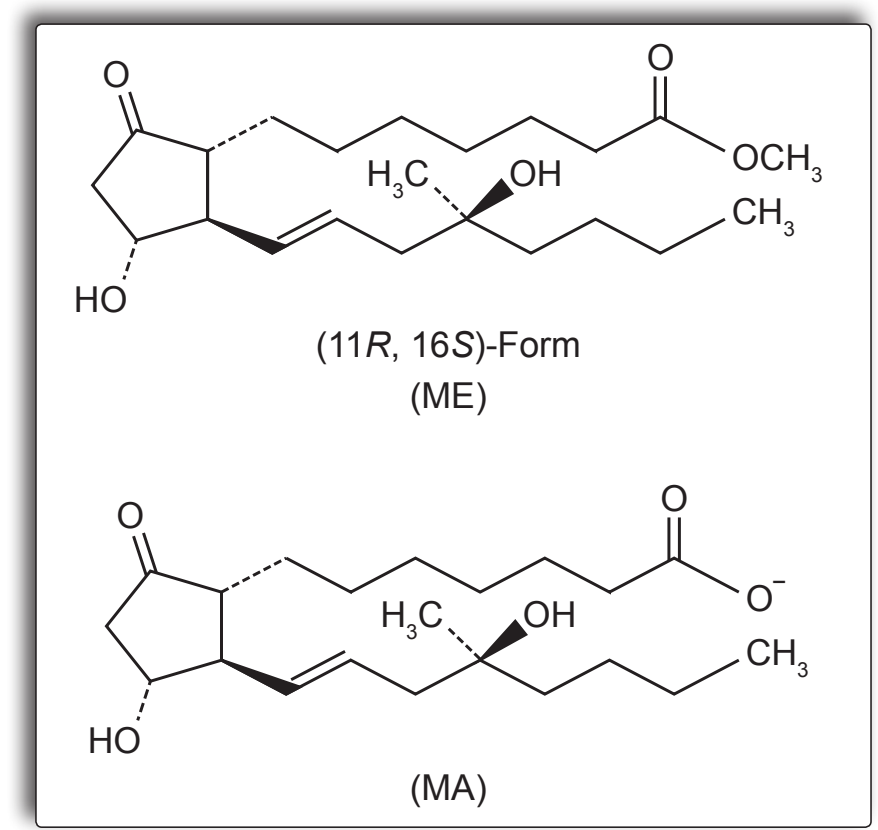

Figura 1. Misoprostol éster (ME) y misoprostol ácido (MA)

solventes tales como agua y metanol en diferentes proporciones, con flujos promedio de $0,3-0,6 \mathrm{~mL} / \mathrm{min}$, dando mejores resultados la mezcla metanol: agua (1:1) (tabla 1).

\section{Espectrofotometría de masas}

Para optimizar las condiciones de ionización por elctrospray (ESI) ${ }^{5}$ negativa para misoprostol ácido, se realizaron escaneos en el cuadrupolo en modo ión negativo. Durante el experimento de infusión directa, la masa espectral para misoprostol ácido reveló un pico a m/z 367,1 amu.

Cuando se experimentó con misoprostol ácido m/z 367,1 amu en modo MRM ${ }^{10}$, la energía de colisión originó un ion hijo de m/z 249,o amu.

\section{Selectividad}

Para evaluar la selectividad se inyectó suero humano control (libre de analito) y suero humano inoculado con misoprostol ácido, los cuales sufrieron el proceso de SPE según las indicaciones del fabricante. Ningún pico de interferencia de compuestos endógenos fue observado durante el tiempo de retención de la muestra con analito en comparación con la muestra blanco. El tiempo de retención de misoprostol ácido fue de 2,2 min. El tiempo de corrido cromatográfico fue de cinco min (figura 2).

\section{Curva de Calibración}

La curva de calibración fue construida usando estándares de calibración de $1 ; 3 ; 5 ; 10 ; 15$ y 20 ppb. Fue preparada determinando la mejor respuesta promedio pico-área vs. concentración además de haber sido adecuada al $y=m x+c$.

\section{Preparación de las muestras}

Las muestras de sangre o suero recolectadas, pertenecientes a casos de posible aborto, fueron procesadas de la siguiente manera:
Tabla 1. Fase móvil en gradiente utilizada en el LC MS-MS.

\begin{tabular}{cccc}
\hline Tiempo & Flujo (mL/min) & \% A (agua) & \%B (metanol) \\
\hline 3 & 0,4 & 95 & 5 \\
3,5 & 0,4 & 5 & 95 \\
3,6 & 0,4 & 5 & 95 \\
5,5 & 0,4 & 95 & 5 \\
\hline
\end{tabular}

Tabla 2. Lecturas obtenidas con la curva de calibración.

\begin{tabular}{cccccc}
\hline & $\begin{array}{c}\text { Lecturas } \\
(\mathbf{p p b})\end{array}$ & Áreas & \multicolumn{2}{c}{$\begin{array}{c}\text { Lecturas } \\
(\mathbf{p p b})\end{array}$} & Áreas \\
\hline 1 & 3,3 & 43,15 & 11 & 3,7 & 49,268 \\
2 & 4,2 & 57,615 & 12 & 13,9 & 198,51 \\
3 & 5,1 & 69,145 & 13 & 7,8 & 106,23 \\
4 & 3,1 & 40,872 & 14 & 16,2 & 231,456 \\
5 & 15,6 & 223,828 & 15 & 11,5 & 163,147 \\
6 & 4,1 & 55,42 & 16 & 18,4 & 265,364 \\
7 & 3,5 & 47,125 & 17 & 12,4 & 176,617 \\
8 & 6,1 & 85,967 & 18 & 8,7 & 122,457 \\
9 & 17,5 & 250,165 & 19 & 13,9 & 197,92 \\
10 & 18,3 & 261,134 & 20 & 15,3 & 220,138 \\
\hline
\end{tabular}

Tabla 3. Correlación de Pearson entre concentración de misoprostol ácido y el área bajo la curva.

\begin{tabular}{lcc}
\hline $\begin{array}{c}\text { Concentración de } \\
\text { misoprostol ácido }\end{array}$ & $\begin{array}{c}\text { Correlación de } \\
\text { Pearson } \\
\text { sig. (bilateral) }\end{array}$ & $0,999^{(* *)}$ \\
\hline
\end{tabular}

** La correlación es significativa al nivel 0,01 (bilateral).

Tabla 4. Concentraciones promedio y coeficiente de varianza hallados para la curva de calibración.

\begin{tabular}{|c|c|c|c|c|c|}
\hline $\begin{array}{l}\text { Concen- } \\
\text { tración }\end{array}$ & ppb & Área & $\begin{array}{c}\text { ppb } \\
\text { promedio }\end{array}$ & $\mathbf{s}$ & $\% \mathrm{CV}$ \\
\hline 1 & 1 & 9,512 & 0,966666667 & 0,08164966 & 8,44651635 \\
\hline 1 & 1 & 9,235 & & & \\
\hline 1 & 0,9 & 8,712 & & & \\
\hline 1 & 1,1 & 10,869 & & & \\
\hline 1 & 0,9 & 8,417 & & & \\
\hline 1 & 0,9 & 8,369 & & & \\
\hline 3 & 3,2 & 41,667 & 3,116666667 & 0,11690452 & 3,75094715 \\
\hline 3 & 2,9 & 36,736 & & & \\
\hline 3 & 3,2 & 41,117 & & & \\
\hline 3 & 3,2 & 41,625 & & & \\
\hline 3 & 3,1 & 40,075 & & & \\
\hline 3 & 3,1 & 40,502 & & & \\
\hline 5 & 5,1 & 68,93 & 4.983333333 & 0.14719601 & 2.95376618 \\
\hline 5 & 5,2 & 69,714 & & & \\
\hline 5 & 4,9 & 65,737 & & & \\
\hline 5 & 5 & 67,436 & & & \\
\hline 5 & 4,8 & 65,348 & & & \\
\hline 5 & 4,9 & 65,917 & & & \\
\hline 10 & 9,8 & 136,633 & 9,933333333 & 0,15055453 & 1,51564964 \\
\hline 10 & 9,9 & 137,884 & & & \\
\hline 10 & 9,9 & 138,766 & & & \\
\hline 10 & 9,8 & 136,926 & & & \\
\hline 10 & 10,2 & 142,664 & & & \\
\hline 10 & 10 & 139,488 & & & \\
\hline 20 & 20,1 & 286,647 & 20 & 0,16733201 & 0,83666003 \\
\hline 20 & 19,8 & 281,633 & & & \\
\hline 20 & 20,2 & 288,025 & & & \\
\hline 20 & 20,1 & 286,072 & & & \\
\hline 20 & 19,8 & 282,415 & & & \\
\hline 20 & 20 & 285,418 & & & \\
\hline
\end{tabular}




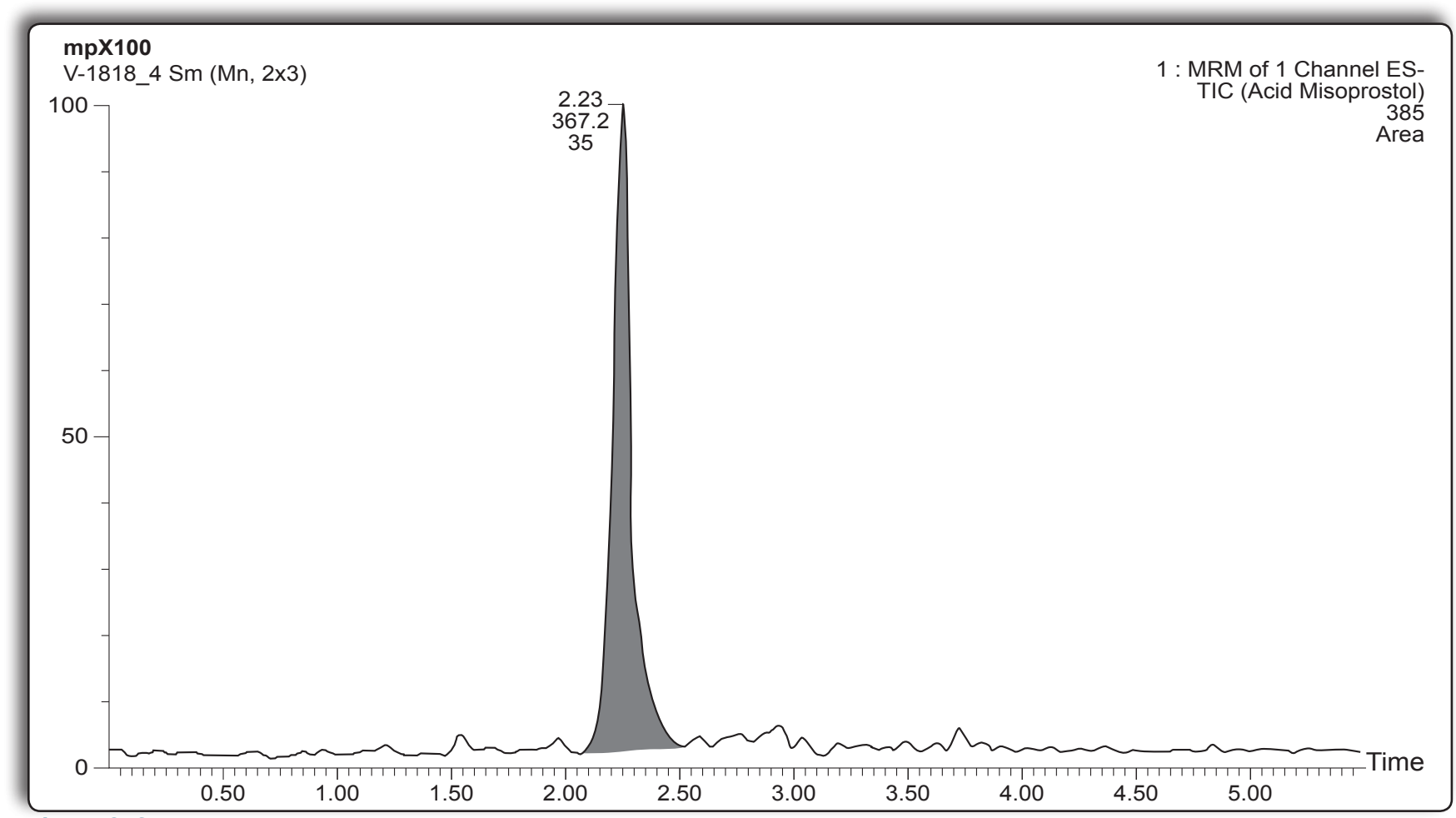

Figura 2. Cromatograma de misoprostol ácido.

1. A partir de $5 \mathrm{~mL}$ de sangre se obtuvo, por centrifugación, 1 $\mathrm{mL}$ de suero que fue sometido a extracción en fase sólida con cartucho HLB de $3 \mathrm{~mL}$, el cual fue pre-acondicionado con $1 \mathrm{~mL}$ de solución de agua:metanol (1:1), lavado con $1 \mathrm{~mL}$ de agua:metanol (9:1) y eluído con $1 \mathrm{~mL}$ de metanol. Terminado el proceso SPE se agregó al eluato $1 \mathrm{~mL}$ de agua y se inyectaron $5 \mu \mathrm{L}$ en el sistema LC-MS/MS

\section{Identificación y cuantificación de misoprostol en suero}

Se usó un sistema LC equipado con desgasificador isobomba con autosampler para inyectar alícuotas de 5 $\mu \mathrm{L}$ de las muestras procesadas. Dicho sistema contaba con una columna Acquity UPLC BEH C18 (1,7 $\mu \mathrm{m} ; 2,1$ x 50 $\mathrm{mm})$, mantenida a temperatura ambiente $\left(24 \pm 2^{\circ} \mathrm{C}\right)$; una fase móvil en gradiente (tabla 1); y un espectrofotómetro de masas de ionización por electrospray (ESI).

La cuantificación se realizó con un detector MS-MS en modo ión negativo (ESI negativo) para misoprostol ácido. El voltaje del cono fue $25 \mathrm{~V}$ y el del gas de colisión fue $20 \mathrm{~V}$.

Para la detección de los iones se utilizaron: el modo de monitoreo de reacción múltiple (MRM), los pares de transición de misoprostol ácido $\mathrm{m} / \mathrm{z}$ 367,1 amu y “daughter ion” m/z 263,o amu. Los datos analíticos fueron procesados por el programa estadístico SPSS v19
Tabla 5. Comparación de medias del área bajo la curva y la concentración de misoprostol ácido.

\begin{tabular}{|c|c|c|c|c|c|c|c|c|c|c|}
\hline & & & & & $\overline{\text { ANOVA }}$ & & Prue & ade T & urkey & \\
\hline & & & Media & $\begin{array}{l}\text { Desviación } \\
\text { estandar }\end{array}$ & & 1 & 3 & 5 & 10 & 20 \\
\hline & uno & 6 & 9,2 & 0,9 & $0,00^{*}$ & & $0,00^{*}$ & $0,00^{*}$ & $0,00^{*}$ & $0,00^{*}$ \\
\hline & tres & 6 & 40,3 & 1,8 & & & & $0,00^{*}$ & $0,00^{*}$ & $0,00^{*}$ \\
\hline Área bajo la & cinco & 6 & 67,2 & 1,8 & & & & & $0,00^{*}$ & $0,00^{*}$ \\
\hline & diez & 6 & 138,7 & 2,2 & & & & & & $0,00^{*}$ \\
\hline & veinte & 6 & 285 & 2,5 & & & & & & \\
\hline & uno & 6 & 1 & 0,1 & $0,00^{*}$ & & $0,00^{*}$ & $0,00^{*}$ & $0,00^{*}$ & $0,00^{*}$ \\
\hline Concentración & tres & 6 & 3,1 & 0,1 & & & & $0,00 *$ & $0,00^{*}$ & $0,00^{*}$ \\
\hline de misoprostol & cinco & 6 & 5 & 0,1 & & & & & $0,00^{*}$ & $0,00^{*}$ \\
\hline ácido & diez & 6 & 9,9 & 0,2 & & & & & & $0,00^{*}$ \\
\hline & veinte & 6 & 20 & 0,2 & & & & & & \\
\hline
\end{tabular}

Métodos estadísticos que se emplearon para analizar los resultados

a. Correlación de Pearson

b. Concentración promedio

c. Coeficiente de varianza

d. Comparación de medias

\section{Soluciones estándar}

Se preparó la solución stock primaria $1,00 \mathrm{mg} / \mathrm{mL}$ de misoprostol ácido en una mezcla de agua:metanol (1:1), grado cromatografía líquida, y se almacenó a $-4^{\circ} \mathrm{C}$. A partir de ella, el día de análisis, se realizaron diluciones con agua:metanol (1:1) para obtener soluciones de trabajo de $1 ; 3 ; 5 ; 10$ y 20 ppb, con las que elaboró la curva de calibración (tabla 4) . Las soluciones de trabajo por duplicado fueron almacenadas aproximadamente $\mathrm{a}-4^{\circ} \mathrm{C}$ por una semana, y cada una fue leída tres veces. 


\section{RESULTADOS}

Los resultados se presentan en las tablas 2-5y en las figuras 2-5.

En la tabla 2 puede visualizarse la concentración menor 3,1 ppb y la concentración mayor 18,4 ppb en suero.

En la tabla 3 se observa que existe una correlación alta positiva y significativa $(0,99 ; \mathrm{p}=0,00<0,05)$ entre concentración de misoprostol ácido y el área de bajo la curva.

En la tabla 4 se observa que los coeficientes de variación para las concentraciones promedio son menores a $15 \%$.

Se presenta como alternativa a la extracción líquidolíquido tradicional, un método extractivo por SPE utilizando el cartucho HLB Oasis Maxi1 300 mg x 3 mL, con el cual se extrajo el analito, eluyéndose con metanol, al cual se agrega agua formando una mezcla metanol:agua (1:1) lista para ser inyectada en el sistema LC. Los resultados de este método son presentados en la tabla 5, observándose que a medida que aumenta la cantidad de misoprostol ácido, la media del área bajo la curva aumenta de manera estadísticamente significativa.

\section{DISCUSIÓN}

La dosis para inhibir la secreción de ácido gástrico es una tableta de misoprostol vía oral $(200 \mu \mathrm{g})$, la cual genera niveles plasmáticos inferiores a los encontrados en este estudio. Para fines abortivos se utilizan tres tabletas $(600 \mu \mathrm{g})$ vía oral y dos tabletas vía vaginal $(400 \mu \mathrm{g})$, haciendo un total de $1000 \mu \mathrm{g}$.

Las principales diferencias entre el método de Zou et $a l^{3}$ y el desarrollado en el presente trabajo son las siguientes:

- Como las muestras aquí procesadas procedieron de mujeresqueintentaronabortar, los valores determinados son el resultado de la asimilación $1 \mathrm{mg}$ de misoprostol; mientras que los de Zou proceden de pacientes que incorporaron o,6 mg.

- Las muestras de Zou fueron plasma, en el presente estudió se usó suero.

- Las muestras de Zou fueron obtenidas de un universo controlado, 20 individuos sanos, en cambio en el presente estudio provinieron de un universo no-controlado.

- En el estudio de Zou et al. se inyectaron alícuotas de $20 \mu \mathrm{L}$

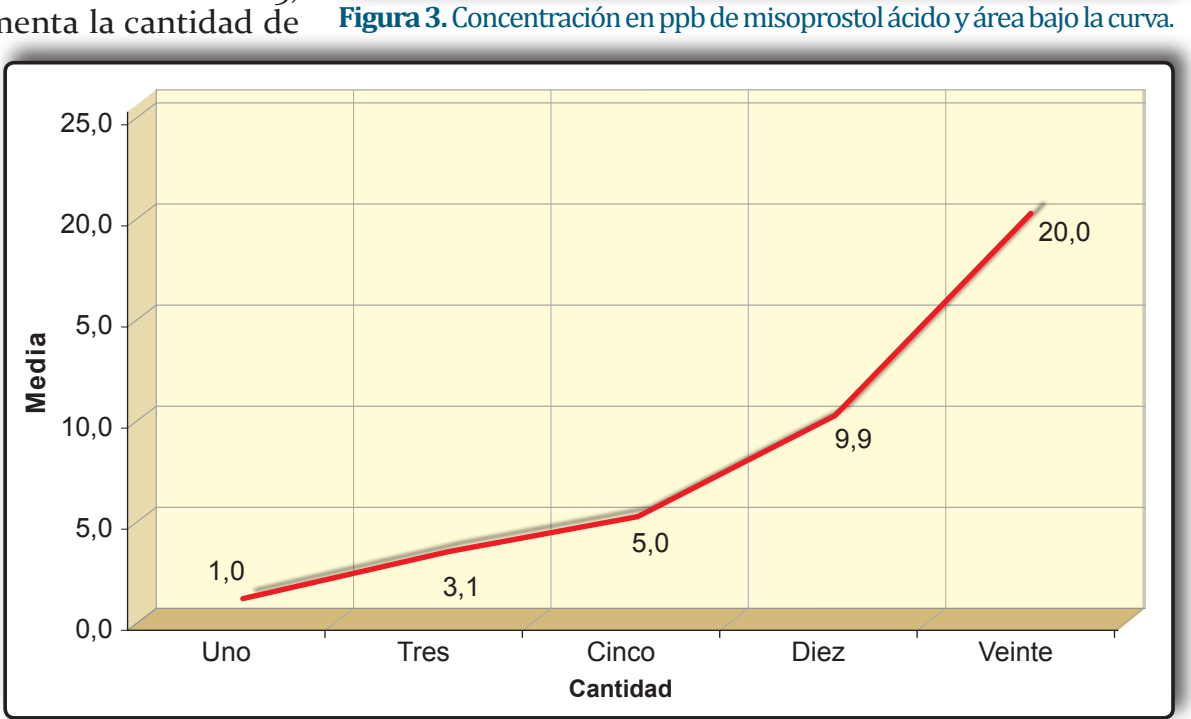

Figura 4. Grafico de líneas de concentración de misoprostol ácido.

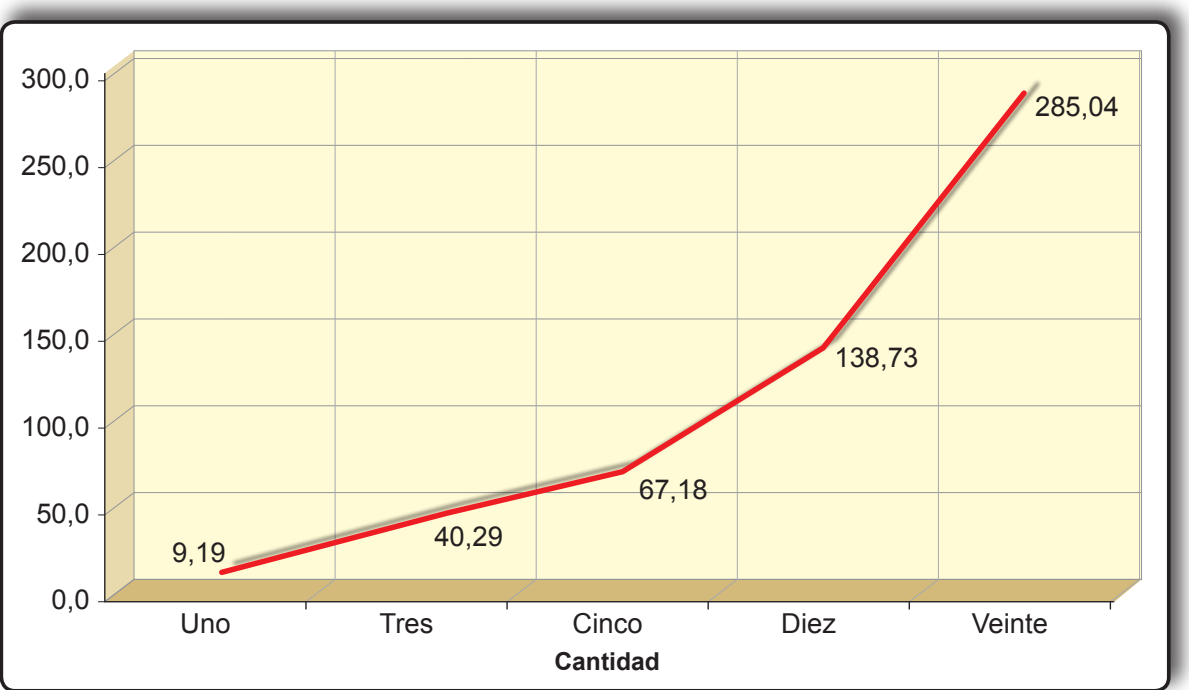

Figura 5. Área bajo la curva de misoprostol ácido. 
al cromatógrafo, en cambio en el presente estudio fueron alícuotas de $5 \mu \mathrm{L}$.

- El equipo utilizado por Zou et al. fue un equipo LCMS-MS híbrido con bomba cuaternaria marca Agilent y detector marca Applied Biosystem, en cambio en el presente trabajo se usó un equipo UPLC MS-MS marca Waters modelo Acquity.

- Las muestras de sangre, en el estudio de Zou et al., fueron tomadas a los 7,5; 15; 30; 45; 60; 90; 120; 180; 240 y 360 minutos luego de la administración, mientras en el presente estudio no pudieron determinarse los tiempos transcurridos entre la aplicación de misoprostol y la extracción de muestras.

- Los valores promedio de concentraciones en el estudio de Zou et al. se reportaron en $\mathrm{pg} / \mathrm{mL}$ para cada uno de los tiempos indicados anteriormente. En cambio en el presente se realizaron lecturas a tiempo desconocido, con valores entre 3,1 a 18,4 ppb.

Las concentraciones encontradas en este estudio (3,1 y 18,4 ppb) no pudieron ser correlacionadas con los valores reportados por Zou et al. Se asume que la razón sería que los tipos de muestras, tiempos de toma de muestra, equipos utilizados, población muestreada, dosis y volúmenes de alícuotas inyectadas en los equipos fueron diferentes en ambas investigaciones.

\section{CONCLUSIONES}

1. Se desarrolló un método cuali-cuantitativo para la determinación de misoprostol ácido en suero humano, a la vez que se desarrolló un método para la extracción de misoprostol ácido a partir del suero de mujeres gestantes que habían ingerido misoprostol éster utilizando un SPE con cartuchos especiales según metodología del fabricante.

\section{REFERENCIAS BIBLIOGRÁFICAS}

1. Grumbach E, Arsenault J, McCabe D. Beginners guide to UPLC: Ultraperformance liquid chromatography. Milford: Waters Corporation; 2009.

2. Tang OS, Gemzell-Danielsson K, Ho PC. Misoprostol: pharmacokinetic profile, effects on the uterus and sideeffects. Int J Gynaecol Obstet. 2007; 99(Suppl 2): S16o-7.
3. Zou Y, Chen X, Song B, Zhong D. Determination of misoprostolacid in human plasma byliquidchromatography coupled to tandem mass spectrometry. J Chromatogr B Analyt Technol Biomed Life Sci 2007; 852(1-2): 122-7.

4. Watkinson G, Hopkins A, Akbar FA. The therapeutic efficacy of misoprostol in peptic ulcer disease. Postgrad Med J 1988; 64(Suppl 1): S6o-77.

5. Mousa H, Walkinshaw S. Major postpartum haemorrhage. Curr Opin Obstet Gynecol. 2001; 13(6): 595-603.

6. Goldberg A, Greenberg M, Darney P, Misoprostol and pregnancy. N Engl J Med. 2001; 344(1): 38-47.

7. Feitsma A., Kanhai H. Misoprostol in the management of postpartum haemorrhage. International Congress Series. 2005; $1279: 358-63$.

8. Weeks A, Fiala C, Safar P. Misoprostol and the debate over off-label drug use. Int BJOG. 2005; 112(3): 269-72.

9. Telepchak M, August T, Chaney G. Forensic and clinical applications of solid phase extraction. New York: Human Press; 2004.

10. Balough M. The Mass Spectrometry Primer. Milford: Waters Corporation; 2009.

11. Vijaya D, Jagadeesh B, Kumar K, Patil U, Bhushan I. Development and validation of highly sensitive method for determination of misoprostol free acid in human plasma by liquid chromatography-electrospray ionization tandem mass spectrometry: application to a clinical pharmacokinetic study. J Chromatogr B Analyt Technol Biomed Life Sci. 2011; 879(26): 2827-33.

12. Bentov Y, Sheiner E, Katz M. Misoprostol overdose during the first trimester of pregnancy. Eur J Obstet Gynecol Reprod Biol. 2004; 115(1): 108-9.

Manuscrito recibido el: 23/03/2016

Aceptado para su publicación el: 19/09/2016

\section{Correspondencia}

Nombre: $\quad$ Q.F. Luis Alberto López Avila

Dirección: $\quad$ Av. Juan Vicente Nicolini 256, Urb.Palao-SMP.

e-mail: luisalbertolopeza@gmail.com 